\title{
TTR
}

Traduction, terminologie, re?daction

\section{TRADTERM, revue du Centre interdépartemental de traduction et de terminologie de la Faculté des lettres et des sciences humaines de l’Université de Sao Paolo. Volume I, nº 1 (1994).}

\section{Sherry Simon}

Volume 7, numéro 2, 2e semestre 1994

Traduire les sociolectes

URI : https://id.erudit.org/iderudit/037190ar

DOI : https://doi.org/10.7202/037190ar

Aller au sommaire du numéro

Éditeur(s)

Association canadienne de traductologie

ISSN

0835-8443 (imprimé)

1708-2188 (numérique)

Découvrir la revue

Citer ce compte rendu

Simon, S. (1994). Compte rendu de [TRADTERM, revue du Centre interdépartemental de traduction et de terminologie de la Faculté des lettres et des sciences humaines de l'Université de Sao Paolo. Volume I, $\mathrm{n}^{0} 1$ (1994).] TTR, 7(2), 229-229. https://doi.org/10.7202/037190ar d'utilisation que vous pouvez consulter en ligne.

https://apropos.erudit.org/fr/usagers/politique-dutilisation/ 
TRADTERM, revue du Centre interdépartemental de traduction et de terminologie de la Faculté des lettres et des sciences humaines de l'Université de Sao Paolo. Volume I, $\mathbf{n}^{0} 1$ (1994).

La variété et l'intensité des études traductologiques au Brésil sont bien représentées par la création de TRADTERM. La nouvelle revue du CITRAT de l'Université de Sao Paolo propose des articles en langue portugaise, avec résumés en anglais. Ce premier numéro s'ouvre sur un hommage à Paulo Ronai, traducteur et homme de lettres d'origine hongroise, récemment décédé. Depuis son arrivée au Brésil en 1940, Ronai s'est dévoué à la pratique de la traduction et à son enseignement, ainsi qu'à la création d'organismes professionnels de traduction (ABRATES, Associaçao Brasileira de Tradutores, et SINTRA, le syndicat national des traducteurs). Auteur d'une dizaine de livres consacrés à la didactique des langues et de la traduction, il fut aussi le traducteur d'une quarantaine d'ouvrages majeurs. Un article de Rosemary Arrojo présente quelques thèses de l'importante école déconstructionniste brésilienne. S'appuyant sur des sources de langues française et anglaise, elle explore les conséquences de la transformation paradigmatique de la théorie de la traduction. Selon la pensée derridienne, la traduction cesse d'être un «problème», pour devenir un riche outil de réflexion sur la signification langagière. Plusieurs études théoriques et une série de textes consacrés à la terminologie complètent ce premier numéro de TRADTERM.

Sherry Simon

Université Concordia 